\title{
Health Care Workers' Use of Electronic Hospital Information System and Their Computer Literacy at the Outpatient Department in District General Hospital Trincomalee in Sri Lanka
}

\author{
D.B.A.S. Jayawardena (MBBS) ${ }^{1}$, S.C. Wickramasinghe (MBBS,MD) ${ }^{2}$, S.R.U. \\ Wimalaratne (BDS,MD) ${ }^{3}$
}

\author{
${ }^{I}$ Deputy Medical Superintendent, District Base Hospital, Panadura, Sri Lanka \\ ${ }^{2}$ Consultant Community Physician and Director (Planning), Address: Ministry of Health \& \\ Nutrition, Suwasiripaya, Rev.Baddegama Wimalawansa Mawatha, Colombo 10, Sri Lanka. \\ ${ }^{3}$ Consultant Community Physician and Director (Health Information), \\ Address: Ministry of Health \& Nutrition, Suwasiripaya, Rev. Baddegama Wimalawansa Mawatha, \\ Colombo 10, Sri Lanka
}

1'ayanthijayawardena@ymail.com, ${ }^{2}$ scwickrama@slt.lk, ${ }^{3}$ sru_wimalaratne@yahoo.com

\begin{abstract}
Objectives: To describe the use of Electronic Hospital Information System (EHIS) by the staff, to assess the competency of them to handle the EHIS and to assess the computer literacy among health care workers at the Out Patient's Department(OPD) in District General Hospital (DGH) Trincomalee. Study design: A cross sectional descriptive study. A competency assessment test and a self administered questionnaire were used. Participants: All the staff members operating the EHIS at the OPD in DGH Trincomalee. Results: Regarding the general use of the EHIS medical officers (100\%) used the EHIS to write prescriptions, $(>70 \%)$ to get the patient's socio-demographic details, enter patient's history to retrieve previous medical records, to obtain what drugs available and what drugs out of stock at the outdoor pharmacy, for notification of diseases and used less frequently to get the laboratory reports (50-70\%). The system was used for 17 tasks out of 20 tasks and most unused tasks were writing the diagnosis according to the ICD-10. Nurses and attendants used the system less than half of the tasks for which the system was functional. The pharmacists use of the system was optimal. Overall respondents' competency of using the system was high (>80\%). Conclusions: Majority of staff members had low level of computer literacy. Majority of them used the system successfully. Recommendations: To strengthen the training program, combat several constraints and upgrade the system, provide digital X-ray imaging and download them to CDs and improved to write the diagnosis according to the ICD-10.
\end{abstract}

Key words: Electronic Hospital Information System, Multi Disease Surveillance, Computer Literacy.

\section{INTRODUCTION}

Good management information system plays a vital role in providing quality health care effectively and efficiently to the patient [1-3]. The Epidemiology Unit in Sri Lanka with the collaboration of WHO initiated Electronic Hospital Information System(EHIS) in $2005[4,5]$. 
The main aim of this project was to strengthen the hospital based health information system by addressing the short comings of the present system such as poor timeliness, lack of information on out patients, problem with multiple reporting and incomplete data [6,7]. The EHIS is successfully functioning at the District General Hospital(DGH) Trincomalee and it is the only hospital in Sri Lanka where Out Patient Department(OPD) has a fully functioning computerized HIS. As the country's aiming towards e-health and paperless hospital information system it is important to study the general use of the system by the health care workers because success of implementation of new systems will totally depend on how much these systems are used by the health care workers in their day today clinical work [8-12]. Objectives of this study were to describe the use of EHIS by the staff, to assess the competency and to assess the computer literacy among health care workers at the OPD in DGH Trincomalee.

\section{METHODS}

This study was a hospital based descriptive cross- sectional study conducted at the OPD in the DGH, Trincomalee. All the staff members who are operating the EHIS at the OPD in the DGH, Trincomalee during the month of September 2010 were included in this study. This included Medical Officers(MO), Nursing Officers(NO), pharmacists/dispensers and attendants/laborers. There were two instruments used in data collection.

\section{Competency Assessment Test}

2. Self Administered Questionnaire

\section{Competency Assessment Test}

The PI used a competency assessment test, a practical assessment where they were asked to feed given data to a database and to perform a task that is expected of the staff to operate the EHIS.

Development of the Competency Assessment Test

PI prepared the assessment tool under the guidance of Director (Health Information) to measure the competency to use the application software and their skills in using computers by discussing with different categories of staff and also by the knowledge gathered during the learning about the system by the system operator.

\section{Self Administered Questionnaire (SAQ)}

Part A: Introduction and socio-demographic characteristics

The characteristics collected were place of residence, age, gender, marital status, religion, ethnicity, professional qualifications and working experience.

Part B: The general information about the use of computers at the working station of the different categories of staff at the OPD who are operating the EHIS including their general understanding about the system. The section asked MOs, NOs, pharmacists/dispensers and attendants/laborers to indicate their frequency of use of computers for 20,12, 10 and 4 general tasks respectively on a six point scale ranging from "Never" to "Our EHIS does not support this task". About the performance of tasks using EHIS, the PI used the same tasks on a six point scale ranging from "Significantly difficult" to "Do not know/Not applicable". This section further elaborated the level of satisfaction of the different categories of staff at the OPD on operating the electronic hospital information system. Therefore the PI used four different questionnaires for four categories of staff.

Part C: In this section the knowledge on computers, use of application software, knowledge on hardware and the use of the computers at the hospital/OPD was assessed. Most of the 
questions used in this questionnaire were close ended ones while few were open ended specially to get their views on the computerized system and to get their suggestions to further improve the system.

Development of the Self Administered Questionnaire:

PI adapted and added few other questions to an existing, validated questionnaire to produce the section covering the general use of the system to function important tasks for which the computer system was functional, self assessed level of performance of these tasks using the system and their user satisfaction [13-15].

PI adopted an existing, validated questionnaire to produce the section covering computer literacy [16,17]. PI formed a different questionnaire for each different category of staff as their knowledge, attitudes, working experience and work was different from each other. Face validity and content validity reached by discussing with the system operators and the several other key personals conversant with the system.

\subsection{Definition of variables}

Use of the EHIS, their self assessed level of performance of tasks using the system. Out of 20 tasks interviewed the PI merged several similar tasks to make the analysis easy and analyzed 12 tasks for medical officers, 07 for nurses, 07 for pharmacists/dispensers and 04 for attendants.

User satisfaction

The user satisfaction was inquired in the questionnaire using five factors, content, accuracy, format, ease of use and timeliness. User satisfaction was scaled as follows,

$\begin{array}{ccc}\text { Self assessed rate of satisfaction } & \text { scale } \\ \text { 1. Never/Almost never } & 00 \\ \text { 2. Seldom } & 01 \\ \text { 3. About half of the time } & 02 \\ \text { 4. Most of the time } & 03 \\ \text { 5. Almost always } & 04\end{array}$

Assessment of competency on using EHIS of different categories of staff

The PI used the competency assessment tool where different tasks were given to different categories of staff ( 6 tasks for MOs, 5 tasks for NOs, 6 tasks for pharmacists/dispensers and 6 tasks for attendants). They were assessed using a 05 point scale, giving a score as described below.

1. Perform the task very easily $\quad-100$

2. Perform the task with ease -75

3. Perform the task after repeated attempts -50

4. Perform the task with great difficulty -25

5. Unable to carry out the task $\quad-00$

\section{Assessment of computer literacy}

The assessment consisted of 15 different questions and answers for these questions were calculated out of 100 . 


\section{RESULTS}

\subsection{General use of EHIS and the level of satisfaction among the staff members}

MOs mostly use the EHIS to write prescriptions (100\%), also very frequently (>70\%) used to get the patient's socio-demographic details, enter patient's history, to retrieve previous medical records, to obtain what drugs available and what drugs out of stock at the outdoor pharmacy and for notification of diseases; they used the system less frequently (50-70\%) to get the laboratory reports and radiological reports, refer patients to other departments and to get the disease morbidity pattern at the OPD as seen in Fig. 1. Also, NOs used the system mostly $(100 \%)$ to get information about patient and to observe what drugs available or not available at the pharmacy; used the system frequently (50-70\%) to get previous records of the patients as in Fig. 2. It can be seen in Fig. 3 that pharmacists/dispensers used the system optimally $(100 \%)$. The attendants used the system very frequently $(>75 \%)$ to give the patient's ID number and to admit the patient as shown in Fig. 4.

FIGURE 1: Frequency of using EHIS to assist in selected tasks by Medical Officers

12. Get the disease pattern of the OPD

\section{Notification of the} diseases

10. Refer patients to other departments

9. Give written instructions to the patients

8. Register codes for diagnosis

7. Write diagnosis according to the ICD-10

6. Observe what drugs available/not available..

5. Write prescriptions

4. Obtain lab and radiological reports

3. Obtain previous records

2. Enter the patient's history of the disease

1. Get the patient's socio demographic details

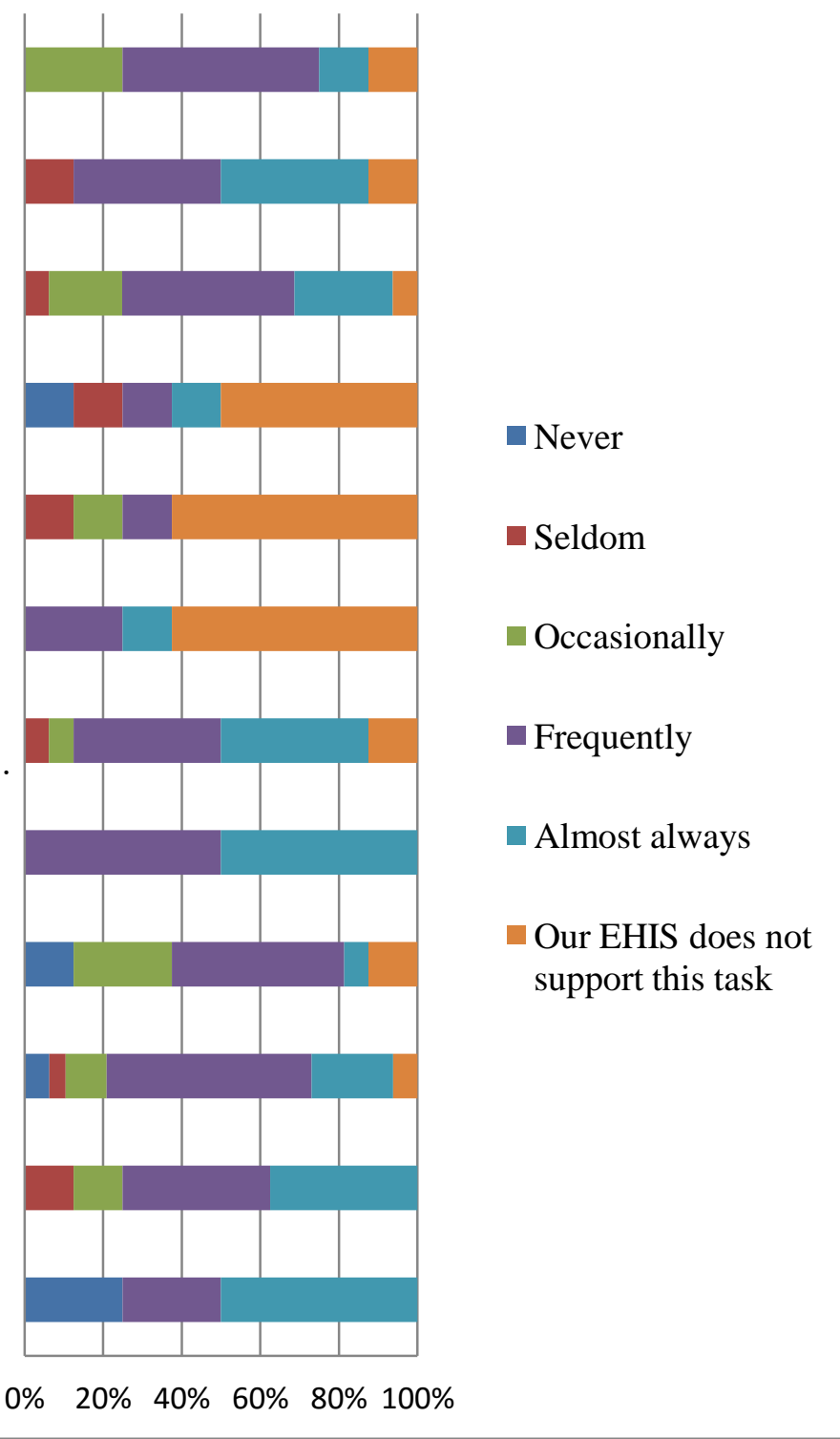

$\begin{array}{llllll}0 \% & 20 \% & 40 \% & 60 \% & 80 \% & 100 \%\end{array}$ 
D.B.A.S. Jayawardena, et.al.

FIGURE 2: Frequency of using EHIS to assist in selected tasks by Nursing Officers

7. Stock balance of drugs

6. Get the prescription

5. Register codes for procedures

4. Observe what drugs available, not available

3. Obtain allergic history of the patients

2. Retrieve previous medical records and lab.

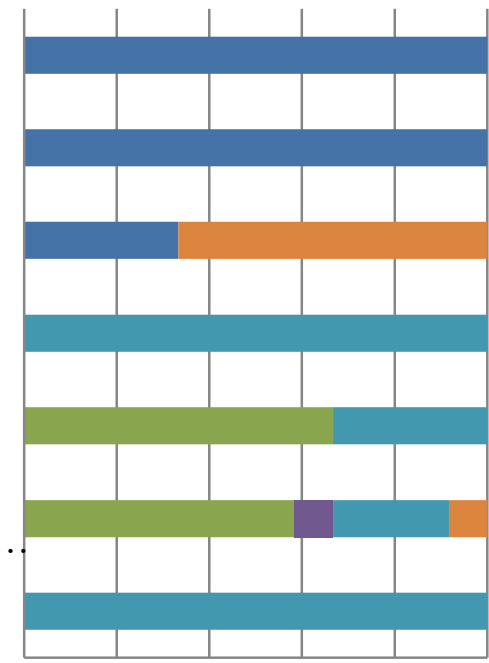

never

- Seldom

- Occasionally

- Frequently

- Almost always

1. Review patient's records

\section{$\begin{array}{llllll}0 \% & 20 \% & 40 \% & 60 \% & 80 \% & 100 \%\end{array}$}

- Our EHIS does not support this task

FIGURE 3: Frequency of using EHIS to assist in selected tasks by Pharmacists/Dispensers

7. Stock balance of drugs

6. Issue medicine to the patients

5. Observe what not available at the pharmacy

4. Observe what drugs available

3. Obtain allergic history

2. Retrieve previous medical reports

1. Review patient's records

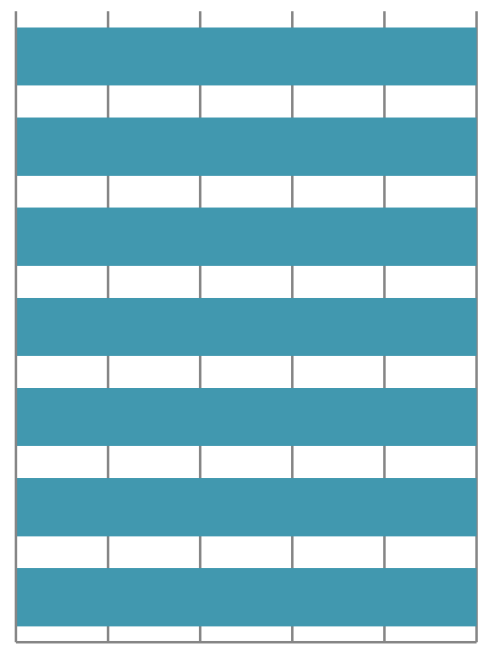

$\begin{array}{llllll}0 \% & 20 \% & 40 \% & 60 \% & 80 \% & 100 \%\end{array}$ never

- Seldom

- Occasionally

- Frequently

- Almost always

- Our EHIS does not support this task 


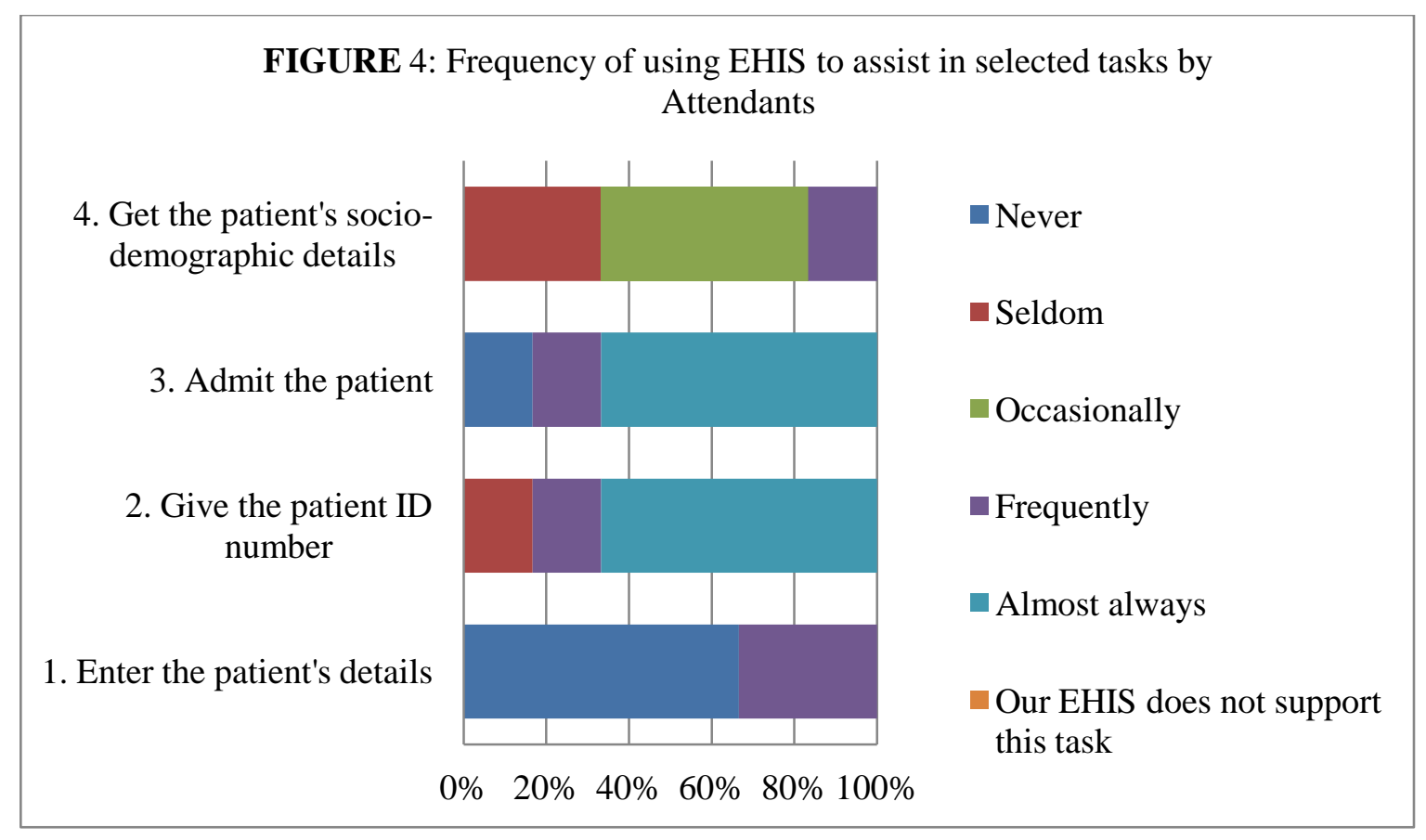

\subsection{Assessment of user satisfaction on using EHIS by different categories of staff}

As Table 01 shows the mean overall score for MOs was 32.5 ( $\mathrm{SD} \pm 1.41$ ). The mean overall score for NOs was $42.1( \pm \mathrm{SD} 7.0)$, for pharmacists/dispensers was $32.5(\mathrm{SD} \pm 1.41)$ and for attendants was 42.3(SD \pm 4.08 ) (Table 01).

TABLE 1: User satisfaction scores obtained by different categories of staff

\begin{tabular}{lllllllll}
\hline Factor & \multicolumn{2}{l}{ Medical officers } & \multicolumn{2}{l}{ Nursing officers } & \multicolumn{2}{l}{$\begin{array}{l}\text { Pharmacists/ } \\
\text { dispensers }\end{array}$} & \multicolumn{2}{l}{ Attendants } \\
& Mean & SD & Mean & SD & Mean & SD & Mean & SD \\
\hline Content & 6.7 & 4.08 & 8.7 & 1.15 & 6.7 & 4.08 & 8.7 & 1.03 \\
Accuracy & 9.2 & 2.04 & 8.7 & 1.15 & 9.2 & 2.04 & 8.5 & 0.84 \\
Format & 5.0 & 3.16 & 8.3 & 1.50 & 5.0 & 3.20 & 8.2 & 0.98 \\
Ease of use & 5.8 & 4.92 & 7.7 & 2.08 & 5.8 & 4.92 & 8.7 & 1.03 \\
Timeliness & 5.8 & 4.92 & 8.7 & 1.15 & 5.8 & 4.92 & 8.3 & 0.82 \\
\hline Total & 32.5 & 1.41 & 42.1 & 7.0 & 32.5 & 1.41 & 42.3 & 4.08 \\
\hline
\end{tabular}

Of the 08 MOs 06 (75\%) were agreed EHIS is worth the time and effort required to use it while $02(25 \%)$ were neutral on it. Of the 03 NOs and 06 pharmacists/dispensers all (100\%) were agreed and of the 06 attendants $05(83.3 \%)$ agreed while $01(16.7 \%)$ were neutral on the statement. The rate of success of the EHIS installed in their department by different categories of staff were as follows, $05(62.5 \%)$ out of 08 MOs rated as good, $02(25 \%)$ as fair and $01(12.5 \%)$ as excellent; all the NOs (100\%) rated as good; $04(66.7 \%)$ of pharmacists/dispensers rated as good and 03 out of $06(50 \%)$ as good and $03(50 \%)$ as excellent by attendants. Almost all the staff members (100\% MOs, $100 \%$ NOs, $100 \%$ Pharmacists/dispensers and $66.7 \%$ of attendants) thought that the quality of the work at the 
D.B.A.S. Jayawardena, et.al.

OPD has increased after installation of the new EHIS except 02 of 06 (33.3\%) attendants thought that the quality has decreased.

\subsection{Assessment of competency on using EHIS of different categories of staff}

The mean summed score of this section for MOs was 90.8, for NOs was 93.9, for Pharmacists/dispensers was 87.0 and for attendants was 88.2 out of 100 (Tables 02 - 05).

TABLE 2: Competency assessment of the Medical Officers

\begin{tabular}{llllllll}
\hline $\begin{array}{l}\text { Descriptive } \\
\text { statistics }\end{array}$ & Total & T1 & T2 & T3 & T4 & T5 & T6 \\
\hline Mean & 90.8 & 95.8 & 95.8 & 82.3 & 86.4 & 87.5 & 96.8 \\
Median & 93.0 & 95.8 & 95.8 & 83.3 & 87.5 & 91.6 & 100.0 \\
Mode & 93.0 & 91.6 & 91.6 & 91.6 & 91.6 & 91.6 & 100.0 \\
SD & 4.63 & 4.45 & 4.45 & 6.95 & 6.20 & 6.29 & 6.20 \\
Minimum & 83.3 & 91.7 & 91.7 & 75.0 & 75.0 & 75.0 & 83.3 \\
Maximum & 95.8 & 100.0 & 100.0 & 91.6 & 91.6 & 91.6 & 100.0 \\
\hline
\end{tabular}

T1 - Enter your password, T2 - Enter patient's ID number, T3 - Enter patient's main complaint and other complaints, T4 - Prescribe three drugs for a patient with doses and duration of treatment, T5 Order two blood investigations, T6 - Save and print the document.

TABLE 3: Competency assessment of the Nursing Officers

\begin{tabular}{lllllll}
\hline $\begin{array}{l}\text { Descriptive } \\
\text { statistics }\end{array}$ & Total & T1 & T2 & T3 & T4 & T5 \\
\hline Mean & 93.9 & 97.2 & 91.7 & 91.7 & 91.7 & 97.2 \\
Median & 95.0 & 100.0 & 91.7 & 91.7 & 91.7 & 100.0 \\
Mode & 86.7 & 100.0 & 83.3 & 83.3 & 83.3 & 100.0 \\
SD & 6.74 & 4.81 & 8.33 & 8.33 & 8.33 & 4.81 \\
Minimum & 86.7 & 91.7 & 83.3 & 83.3 & 83.3 & 91.7 \\
Maximum & 100.0 & 100.0 & 100.0 & 100.0 & 100.0 & 100.0 \\
\hline
\end{tabular}

T1 - Enter your password, T2 - Enter patient's ID number, T3 - Retrieve patient's record, T4 - Enter the record of treatment carried out eg. nebulize the patient/ give IV Hydrocortisone, T5 - Save the records.

TABLE 4: Competency assessment of the Pharmacists/Dispensers

\begin{tabular}{llllllll}
\hline $\begin{array}{l}\text { Descriptive } \\
\text { statistics }\end{array}$ & Total & T1 & T2 & T3 & T4 & T5 & T6 \\
\hline Mean & 87.0 & 91.6 & 91.6 & 86.1 & 79.2 & 81.9 & 91.6 \\
Median & 91.7 & 100.0 & 100.0 & 83.3 & 83.3 & 83.3 & 100.0 \\
Mode & 91.7 & 100.0 & 100.0 & 75.0 & 83.3 & 83.3 & 100.0 \\
SD & 1.06 & 1.29 & 1.29 & 1.14 & 1.15 & 6.27 & 1.29 \\
Minimum & 72.2 & 75.0 & 75.0 & 75.0 & 58.3 & 75.0 & 75.0 \\
Maximum & 97.2 & 100.0 & 100.0 & 100.0 & 91.7 & 91.7 & 100.0 \\
\hline
\end{tabular}

T1 - Enter your password, T2 - Enter patient's ID number, T3 - Retrieve patient's record and the prescription, T4 - Enter the record of Issued drugs according to the prescription, T5 - Stock balancing of drugs, T6 - Save the records and Update 
TABLE 5: Competency assessment of the Attendants

\begin{tabular}{llllllll}
\hline $\begin{array}{l}\text { Descriptive } \\
\text { statistics }\end{array}$ & Total & T1 & T2 & T3 & T4 & T5 & T6 \\
\hline Mean & 88.2 & 91.7 & 90.3 & 79.2 & 90.3 & 84.7 & 93.1 \\
Median & 88.2 & 91.7 & 91.7 & 79.2 & 91.7 & 87.5 & 91.7 \\
Mode & 81.9 & 91.7 & 91.7 & 66.7 & 91.7 & 91.7 & 91.7 \\
SD & 4.71 & 5.27 & 6.27 & 1.15 & 6.27 & 9.74 & 3.40 \\
Minimum & 81.9 & 83.3 & 83.3 & 66.7 & 83.3 & 66.7 & 91.7 \\
Maximum & 94.4 & 100.0 & 100.0 & 91.7 & 100.0 & 91.7 & 100.0 \\
\hline
\end{tabular}

T1 - Switch on the computer, T2 - Enter your password, T3 - Enter patient's name, age, gender, date of birth, NIC number, religion, address, and village using the key board, T4 - Find out patient's ID number using the mouse properly, T5 - Retrieve patient's previous records and get the PID number when PID is not available, T6 - Save the records you entered.

\subsection{Assessment of computer literacy of different categories of staff}

The mean total score of this section for MOs were $66.7 \%$; Pearson's correlation of computer literacy with the competency of use of computers was 0.28 ( $\mathrm{P}=0.502)$, for NOs were 46.7; Pearson's correlation of computer literacy with the competency of use of computers was 0.962 ( $\mathrm{P}=0.176)$, for Pharmacists/dispensers were 42.2; Pearson's correlation of computer literacy with the competency of use of computers was $-0.376(\mathrm{P}=0.463)$ and for attendants were 47.8 Pearson's correlation of computer literacy with the competency of use of computers was $-0.036(\mathrm{P}=0.946)($ Table 06).

Table 06: Computer literacy of different categories of staff

\begin{tabular}{lcccr}
\hline $\begin{array}{l}\text { Descriptive } \\
\text { statistics }\end{array}$ & \multicolumn{4}{c}{ Category of staff } \\
\cline { 2 - 5 } & $\begin{array}{c}\text { Medical } \\
\text { officers }\end{array}$ & $\begin{array}{c}\text { Nursing } \\
\text { officers }\end{array}$ & $\begin{array}{c}\text { Pharmacists/ } \\
\text { dispensers }\end{array}$ & Attendants \\
\hline Mean & 66.7 & 46.7 & 42.2 & 47.8 \\
Median & 70.0 & 40.0 & 33.3 & 50.0 \\
Mode & 40.0 & 33.3 & 26.7 & 20.0 \\
SD & 2.49 & 1.76 & 2.01 & 2.40 \\
Minimum & 40.0 & 33.3 & 26.7 & 20.0 \\
Maximum & 100.0 & 66.7 & 73.3 & 73.3 \\
\hline
\end{tabular}

\section{DISCUSSION}

4.1 General use of EHIS by the staff members at the OPD

MOs mostly use the EHIS to write prescriptions (100\%). The mostly unused functions by Norwegian doctors were repetitive tasks such as writing prescriptions even though these functions were apparently well suited for computers [13]. However, the use of EHIS at the psychiatric hospital in Israel was much more advanced [18].

In this study the EHIS was mainly used to get the patient's socio-demographic details, to obtain what drugs available/out of stock at the outdoor pharmacy and for notification of diseases and used less frequently to get the laboratory/radiological reports and to get the disease morbidity pattern at the OPD but overall the system was used for 17 tasks out of 20 tasks for which the system was functional by $>50 \%$ of MOs in contrast the Norwegian doctors used the system less than half of the tasks and mainly used for reading patient data [13]. 
The system does not provide facilities to write the diagnosis according to the ICD-10 similar to the study in Norwegian hospitals where some of these functionality not being implemented locally in some systems [13]. Overall respondents' competency of using the system were high $(>80 \%)$. Nurses had the highest level of competence $[19,20]$. The mean total score of computer literacy for MOs was 66.7 out of $100(\mathrm{SD} \pm 2.49)$ but the Norwegian doctors' mean summed score of this section was 72.2[13]. Only the MOs have $>50 \%$ and all other three categories of staff had mean total score of $<50 \%$ in this section.

\subsection{Limitations of the study}

The PI found it difficult to find a place to conduct the pre test and therefore pretested only their understanding of wording of the questionnaire. The PI assessed their level of computer literacy, use of the system, level of satisfaction through self rated questionnaire. This self rating method carries a certain risk of misinterpretation and bias.

\section{CONCLUSION AND RECOMMENDATIONS}

- This cross sectional study of EHIS at the OPD, has contributed to a better understanding of the relationship between the use of the system, their level of performance, their level of satisfaction, level of competency of using the system and their level of computer literacy.

- The study results revealed an average level of use of the system by medical officers, nursing officers and attendants but the use of the system by pharmacists/dispensers was optimal. The majority of staff was competent to use the system even though their participation to the basic training program was not satisfactory. Most of them were not satisfied with the training they received.

- Majority of staff members had low level of computer literacy. Even though their computer literacy was low majority of them used the system successfully.

\subsection{Recommendations}

- The low level of use of the system could be explained by the lack of training received about the system. Therefore the hospital management first has to strengthen the training program for the staff.

- Make doctor's signature if possible to come into the prescription.

- The system can provide digital X-ray imaging and download them into a CD thus save X-ray films. Therefore the cost of the radiological films can be minimized.

- The system can be improved to write the diagnosis according to the ICD-10 at the OPD and thus to improve the quality of OPD work.

\section{REFERENCES}

1. T. Lippeveld, et al., Design and implementation of health information systems. Geneva: World Health Organization, 2000.

2. J.C Wyatt, Hospital information management: the need for clinical leadership, British Medical Journal, vol. 311, pp. 175-178, 1995.

3. C. Eelpierre et.al, A systematic review of computer-based patient record system and quality care: more randomized clinical trials or a broader approach?, International Journal for Quality in Health Care, vol. 16, no. 5, pp. 407-416, 2004.

4. Assessing the National Health Information System: An assessment tool. 2008. WHO: Geneva [Online]. [cited 2010 December 04, 6.23pm]; Available from URL: http://www.who.int/healthmatrics/en

5. Components of a strong health information system, a guide to the HMN Framework. Health Metrics Network: Geneva [Online]. [cited 2010 April 5]; Available from URL: http://www.who.int/healthmatrics/en 
D.B.A.S. Jayawardena, et.al.

6. Introduction of Multi Disease Surveillance/ Health Information System, 2008. Epidemiology Unit, Ministry of Healthcare and Nutrition, Sri Lanka. [Online]. [cited 2010 April 05]; Available from: http://www.epid.gov.lk/MultiDiseaseSurveillance.htm

7. M.H. Abusyeed, G.K. Kumara and S. Kanamori, Evaluation of Electronic Hospital Information System in Polonnaruwa, Trincomalee, Batticoloa and Kalmunai. A Field Mission Report, 2008.

8. P. Littlejohns, J.C. Wyatt and L. Garvican, valuating computerized health information systems hard lessons still to be learnt, British Medical Journal, vol. 326, pp. 860-63, 2003.

9. $\quad$ S.J. Jay and J.G. Anderson, Computerized health information system: their future role in medicine, Journal of the Royal Society of Medicine, vol. 75, no. 5, pp. 303$305,1982$.

10. R.D. Cork R.D, W.M. Detmer and C.P. Friedman, Development and initial validation of an instrument to measure physicians' use of, knowledge about and attitude toward computers, Journal of American Medical Informatics Association, vol. 5, pp. 164-176, 1998.

11. D.W. Young, What makes doctors use computers?: discussion paper, Journal of the Royal Society of Medicine, vol. 77, pp. 663-667, 1984.

12. M.A. Malik and H.R. Khan, Understanding the implementation of An Electronic Hospital Information System in a developing country. A Case study from Pakistan, $32^{\text {nd }}$ Australian Computer Science Conference(ACSC), 2009.

13. H. Laerum, G. Ellingsen and A. Faxvaag, Doctor's use of electronic medical records systems in hospitals: cross sectional survey, British Medical Journal, vol. 323, no. 7325, pp. 1344-1348, 2001.

14. R.F. Cork, W.M. Detmer and C.P. Friedman, Development and initial validation of an instrument to measure Physician's use of, knowledge about and attitudes toward computers, Journal of the American Medical Informatics Association, vol. 5, no. 2, 164-176, 1998.

15. M. Top and O. Gider, Nurses' views on Electronic Medical Records (EMR) in Turkey: An Analysis According to Use, Quality and User satisfaction, Journal of Medical Systems, [Internet]. [cited on 2011February 12]; Available from: http://www.springerlink.com/content/a88544rp61458570/

16. A. Satharasinghe, Computer literacy of Sri Lanka. Department of Census and Statistics, Sri Lanka. Available Online at: www.statistics.gov.lk/cls2004/index.htm

17. Computer Literacy Census Schedule.pdf. 2006. Census on computer literacy of academic staff of government schools, approved private schools and perivenas in Sri Lanka-2006. Department of Census and Statistics and Ministry of Education [Online]. [cited 2010 April 05]; Available from URL:

http://statistics.sltidc.lk/ddibrowser/?section=accesspolicy\&id=1249\#questionnaires

18. I. Modai, M. Ritsner, H. Silver and R. Kurs, A Computerized Patient Information System in a Psychiatric hospital, Psychiatric Services, vol. 53, pp. 476478, 2002.

19. M. Rajesh, R. Sarosh and S.K. Kolay, Hospital information system in Medicare - An experience at TATA Main hospital, Jamshedpur, 2009.

20. O.G. Otieno, H. Toyama, M. Asonuma, M. Kanai-Pak and K. Naitoh, Nurses' views on the use, quality and user satisfaction with Electronic medical records: questionnaire development, Journal of Advanced Nursing, vol. 60, no. 2, pp. 209219, 2007. 